body is best suited for this or that trade or occupation, and for residence in this or that part of the world. Then we shall train men so that we shall no longer send them into occupations with types of body unfitted for the conditions of that occupation, and consequently we shall be spared the misery and loss of those numerous break-downs from unsuitability of type that are now daily brought before us. Yanchester.

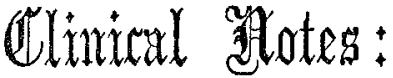

\section{MEDICAL, SURGICAL, OBSTETRICAL, AND THERAPEUTICAL.}

\section{REMOFAL OF URETHRAL CALCULUS OF UNUSUAT SIZE. \\ Br Walter Henry Brown, \\ ASSISTANT SURGEON, LEEDS GENERAL INFIRMARY.}

THE patient, a man aged thirty-six years, married, and the father of two children, came to me complaining of pain and difficulty in micturition. The condition had existed for ten years past, but had greatly increased during the last three years. He brought with him a sample of his urine, which was alkaline, offensive, and contained much pus and albumen. He had been following his employment of insurance agent up to the time of my seeing him. On examination I found a large hard swelling on the under surface of the penis, extending from the glans backwards for a distance of about three inches. He told me that the swelling had existed for some years (he could not say how many), and had gradually got larger. The meatus was closed by warty growths, and I failed to pass even a fine probe. He further informed me that he now passed urine drop by drop. Suspecting calculus, I sent him home, and later in the day had him put under ether, when, after slitting up the meatus, I removed a stone

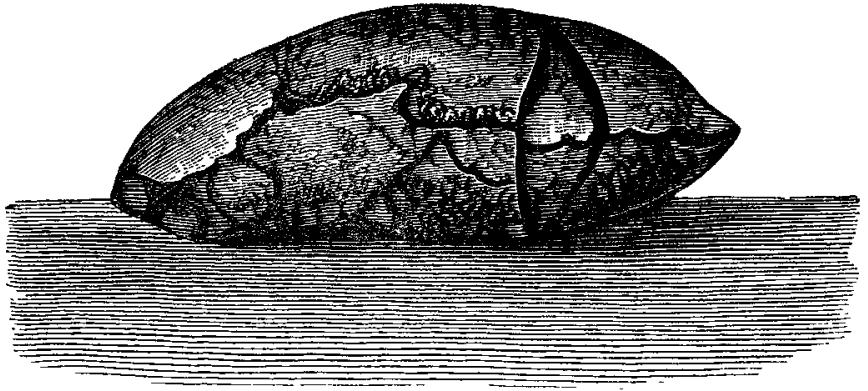

Actual size.

weighing 265 graing, and measuring two inches and a quarter in length, and two inches and a half in circumference at its widest part. Mr. H. A. Smith, one of the house surgeons of the Infirmary, kindly made for me the accompanying sketch, which gives a good idea of the shape and size of the stone. The after history is unimportant, the man making a rapid recovery and the urine clearing within a few days of the operation.

The points of interest which occur to me are:-1. The unusual size of the stone and its position; the recorded cases of large urethral calculi mention them as having been either in the perineum or scrotum. 2. The fact of the man being able to endure the presence of this large calculus in the urethra, of its being apparently no hindrance to sexual intercourse, and, until very recently, not sufficiently painful to compel him to seek relief.

\section{OY THE ESSENTIAL NATURE OF CERTAIN DISEASES} OF THE SKIN.

Br T. Fredertck Pearse, M.D., M.R.C.P.Lond.

MaNY will agree that too much attention is often bestowed upon the clinical symptoms and morbid anatomy of certain diseases of the skin, while the exciting or determining cause is left practically unconsidered. We notice, for example, erzama arising under a varistiy of conditionssuch as that of rheumatism, gout, and external irritation.
Nevertheless, we are apt to label the appearance "eczema" and consider we have got a distinct pathological process. In one sense, perhaps, we may be said to have a particular type of structural change in the eczematous group and another distinct change in the psoriasis group, but my contention is that just as the word "dropsy" only conveys a very general meaning of a patient's condition, so the terms "eczema" and "psoriasis" similarly designate but groups of symptoms without definite pathological indications. We recognise a gouty bronchitis, and ought to treat it as for gout, and not as an inflammatory affection. When we recognise the gouty eczema, there is too much tendency to treat the local condition, and not to pay sufficient regard to the gouty state upon which the local changes depend. To take another example. At one time the joint affections of acute rheumatism, though admitted as part of a general state, were thought to require combating by local treatment. Now, however, we have found that the joints themselves require no local treatment whatever, and that we relieve them by overcoming the rheumatic process upon which these and other symptoms depend. Those who are engaged in the study of diseases of the skin will have $\operatorname{com} \theta$ across cases of eczema which remain unrelieved, or at any rate uncured, by any local application, but which rapidly recover by the internal administration of the salicyIates of hydrogen or soda. In these cases we mey have a local state exactly similar to all intents and purposes to that arising from gout or other causes, but there is a distinct pathological process which we know as rheumatism underlying it. I am quite confident that there are other cases, again, termed "eczema" which are dependent upon influences from the nervous centres. We recognise that a very large number of cases of eczema are associated with some kind or other of intestinal disturbance. Many of these we treat successfully, but there are others in which we do not get at the fons et origo mali, and which remain an opprobrium to our art. Much the same may be said of other groups besides the eczematous. We know the cause of many diseases of the skin, but what I wish to lay stress upon is that though the terms "eczematous," "lichenous," " herpetic," "furuncular," \&c., applied to groups of symptoms, may be useful for instruction, they are absolutely misleading if considered as distinct pathological processes, requiring a special line of treatment for each. Just as we call a particular form of joint affection an "arthritis" and a collection of serum in the tissues "dropsy," so ought we to apply the term "eczema" merely to certain clinical appearances of the skin.

I am quite aware that there is nothing new in the above remarks to sanction them for public print, but my object in bringing them forward is to advocate a classification and nomenclature based upon the etiology of diseases of the skin, rather than upon groups of symptoms or morbid anatomical changes. At some future date I hope to be able to suggest a classification founded on these lines.

Manchester-square, $\mathrm{W}$.

\section{A CASE OF FRACTURE OF SKULL; TREPHINING; RECOVERY.}

By A. J. Poptert, M.R.C.S.

ON the afternoon of June 3rd, a young farm labourer, whilst "skylarking" with other lads in a stable, fell, and was kicked on the head by a horse and rendered unconscious. He was dragged out of the reach of the animal's hoofs, but remained insensible for about ten minutes, when he slowly regained consciousness, and was carried into the neighbouring farmhouse. I saw him about two hours after the accident. His condition was then as follows. He was conscious, suffering apparently from shock ; very pale; temperature $97.5^{\circ}$; pulse 48 ; and he was bleeding from a ragged wound in the scalp about the region of the middle of the anterior border of the right parietal bone; there was no paralysis. An examination of the wound by the finger discovered a sharp edge of broken bone about half an inch long, with depression of neighbouring bone. My brother, Mr. Alfred Popert, who saw the patient with me, and who all through the case rendered me much assistance, agreed that the trephine was indicated, not so much with a view of raising the depressed bone as to remove the loose fragments and splinters which the concentrated localised nature of the blow rendered probable. Accordingly the patient was anæsthetised, the scalp wound enlarged, and the injured 